\title{
Elementos de flexibilidade em contratos de terceirização logística: o caso de uma empresa de telecomunicações
}

\author{
Renata Albergaria de Mello Bandeira ${ }^{\text {** }}$, Luiz Carlos Brasil de Brito Mello ${ }^{\text {, }}$ \\ Antonio Carlos Gastaud Maçada ${ }^{c}$ \\ a*re.albergaria@gmail.com, IME, Brasil \\ bluiz.brasil@gmail.com, UFF, Brasil \\ cacgmacada@ea.ufrgs.br, UFRGS, Brasil
}

\section{Resumo}

0 artigo analisa, através da técnica de estudo de caso, a terceirização logística em uma empresa de telecomunicações. Inicialmente, são discutidos os cuidados e a importância do contrato de terceirização, segundo abordagem da economia dos custos de transação. Analisam-se as possíveis causas das falhas na contratação, e sugerem-se providências para evitar repetições em implementações semelhantes. A experiência adquirida indica que um erro primordial, na opinião dos autores, refere-se à falta de definição da estratégia a ser seguida pela organização em relação ao modelo de contratação. Essa definição é uma etapa fundamental, já que o contrato deve estar alinhado à estratégia.

Palavras-chave

Logística. Terceirização. Contratação. Operador logístico.

\section{Introdução}

A indústria de operadores logísticos ampliou, globalmente, sua oferta de serviços e cresceu $10 \%$ ao ano entre 1995 e 2007 (BOT; NEUMANN, 2007). Em 2008, mesmo com a crise econômica, cresceu 6,5\%, mas, em 2009, observa-se uma redução do faturamento desse mercado devido ao menor volume de transações no comércio internacional (DIBENEDETTO, 2009). Contudo, a recuperação econômica de 2010 reflete no crescimento do setor de logística e da indústria de operadores logísticos (BERMAN, 2010). No Brasil, este mercado também apresenta crescimento expressivo, tendo aumentado seu faturamento de $2007 \mathrm{em}$ 20\% (CENTRO..., 2008). Em 2010, 63 bilhões de dólares - aproximadamente 7\% do Produto Interno Bruto brasileiro - foram destinados a contratos de terceirização logística, um nível semelhante aos índices europeus (65\%) e asiáticos (62\%) (BARROS, 2009).

Devido ao maior volume de negócios, bem como à oferta de serviços mais sofisticados pelos operadores, que passaram a atender a demandas específicas de determinados clientes e a dedicar ativos para operações customizadas, as negociações contratuais para terceirização logística passaram a exigir uma abordagem distinta (ABRAHÃO, 2005). As formas de contratação de operadores logísticos se diferenciam devido ao grande impacto no desempenho das contratantes e ao alto investimento envolvido (LIEB; BENTZ, 2005).

Os contratos de terceirização logística têm duração de longo prazo, variando entre cinco e dez anos (ABRAHÃO, 2005). Portanto, há possibilidade de muitas mudanças no contexto econômico e político, que podem afetar diretamente o processo de contratação. Allen e Chandrashekar (2000) destacam a impossibilidade de previsão de todas as mudanças à qual a cadeia de suprimentos estará susceptível em longo prazo. Assim, a introdução de dispositivos de flexibilidade nos contratos de terceirização logística tem sido propugnada como benéfica (BARTHÉLEMY; QUÉLIN, 2006). A gestão de contratos é fundamental para minimizar riscos, aumentar a segurança, garantir bons resultados e reduzir os custos de terceirização 
logística. A utilização de elementos que promovam a flexibilidade é essencial para o desenvolvimento de contratos mais ágeis, além de garantir a segurança e resguardar o interesse das partes envolvidas (WATER; PEET, 2006).

Nesse contexto, esta pesquisa busca responder à seguinte questão: que elementos permitem a flexibilidade na formulação de contratos de terceirização logística? Apesar do número de publicações sobre terceirização logística ter expandido nos últimos 15 anos (MALONI; CARTER, 2006), ainda são poucas as pesquisas sobre contratos de terceirização logística (JANÉ; OCHOA, 2006). 0 presente artigo é um estudo empírico que utiliza técnicas qualitativas para analisar a importância das flexibilidades para a formulação de contratos de terceirização logística. Os capítulos 2 e 3 apresentam a importância e os conceitos relacionados a tais contratos. 0 capítulo 4 trata da questão da flexibilidade nos contratos logísticos. Através do estudo de caso em uma empresa de telecomunicações, analisa-se a forma que o processo de terceirização logística foi conduzido (capítulos 5 e 6). Enfim, apresentam-se sugestões para aumentar a eficácia do processo quando aplicado a outras empresas (capítulo 7).

\section{A importância dos contratos de terceirização logística}

Cada vez mais, operadores logísticos assumem parcelas importantes das atividades logísticas das empresas contratantes (ROBLES; FISCHMANN, 2001). Contudo, essa atitude não implica na simples transferência das responsabilidades para terceiros. Trata-se de um difícil trabalho de parceria que requer intensa troca de informações e contínua adaptação (NOVAES, 2004).

Abrahão (2005) aponta que o relacionamento entre contratantes e operadores logísticos, na realidade, está longe de caracterizar verdadeiras parcerias estratégicas, apresentando uma interação dinâmica e, muitas vezes, contraditória entre as partes. Esses relacionamentos costumam ser de longo prazo, marcados por forte regulação e coordenação, cujas regras e mecanismos de controle são estabelecidos em contratos detalhados.

Prahinski e Benton (2004) afirmam que as relações entre operadores logísticos são alianças estratégicas, cujo relacionamento se baseia em cooperação e confiança. Coughlan et al. (2002) consideram que a base da aliança é a confiança na honestidade das partes e no interesse no bem-estar alheio, exigindo assim compromisso genuíno. Há evidência teórica de que a aplicação de práticas de gestão, que se baseiam nos conceitos de cooperação, comprometimento e confiança, implica em melhor desempenho da cadeia de suprimentos (CHEN; HUM; SUN, 2001; PRAHINSKI; BENTON, 2004; HANDLEY; BENTON, 2009). Contudo, Hingley (2005) alerta sobre o risco de considerar que o relacionamento da cadeia ocorre apenas com base na cooperação e na confiança, ignorando relações existentes que são muito apropriadas para certos contextos.

Autores como Craig e Willmott (2005), Jané e Ochoa (2006), Ellram, Tate e Billington (2008), Williamson (2008) e Schoenherr (2010), cuja fundamentação teórica se baseia na economia dos custos de transação (ECT), defendem a importância do contrato para regular as relações entre os operadores e os contratantes, mesmo que estes formem uma aliança. Segundo a ECT, a racionalidade limitada e o oportunismo são pressupostos essenciais sobre os atores engajados em transações (BARNEY; HERSTERLY, 2004). Assim, os tipos de contratos e mecanismos de governança são ferramentas para reduzir os riscos de comportamento oportunista.

Van Hoek (2000) verificou uma correlação positiva entre o aumento da terceirização logística e o uso de contratos. Para Jané e Ochoa (2006) e Schoenherr (2010), a relação entre o operador e o contratante costuma ser pautada por um contrato de terceirização, mesmo nos casos em que esses relacionamentos formam alianças estratégicas.

A maior complexidade operacional dos serviços logísticos, a ampliação do escopo dos serviços prestados e a aplicação de novas tecnologias são refletidas no aumento do valor agregado desses serviços e no aprofundamento do relacionamento entre contratante e contratada (ANDERSSON; NORRMAN, 2002). Esse novo perfil de operação amplia a importância das condições e cláusulas contratuais, devido ao seu impacto no desempenho, qualidade e eficiência do processo terceirizado (SCHOENHERR, 2010). Dessa forma, contratos capazes de minimizar os riscos estratégicos e de melhorar o alinhamento entre os objetivos das partes envolvidas são fundamentais para o bom relacionamento na cadeia de suprimentos (BARTHÉLEMY, 2003; HANDLEY; BENTON, 2009). A seguir, aborda-se o conceito de contrato de terceirização logística, sendo apresentadas suas principais características.

\section{0 contrato de terceirização logística}

0 desenho de um contrato consiste na configuração dos termos que regem um relacionamento interorganizacional. Maltz (1995) classifica a aquisição de serviços logísticos como uma atividade complexa 
que se diferencia da compra de componentes e bens, pois os operadores fornecem uma série de transações, exigindo do contratante interfaces e monitoramentos mais sofisticados. Logo, o desenho do contrato torna-se cada vez mais importante na terceirização logística.

Com o aumento das responsabilidades assumidas pelos operadores, os contratos logísticos se diferem daqueles tradicionalmente utilizados pelos departamentos de Compras (PALANEESWARAN et al., 2002). As formas de contratação se diferenciam por estarem submetidas a questões próprias do setor, tanto de natureza técnica como de implicações comerciais, e por se situarem em um contexto de implementação de médio a longo prazo com comprometimento de recursos. Craig e Willmott (2005) ressaltam que, de acordo com o tamanho, a complexidade e a importância do processo de terceirização logística, é essencial a aplicação de técnicas de negociação rigorosas, tal como as utilizadas em processos de fusões, aquisições e joint-ventures.

Schoenherr (2010) destaca que um contrato logístico deve ser específico e detalhado, além de considerar possíveis eventualidades. Para Boyson (1999), os contratos logísticos incluem garantias que se referem às questões administrativas, comerciais, técnicas, culturais, além de estabelecer multas por quebra de contrato e determinar prazos para a interrupção da prestação de serviços. Os clientes também buscam definir cláusulas que determinem as condições para o rompimento dos contratos, condições essas que contemplam fatores como a qualidade da prestação de serviços.

Segundo Ward e Chapman (1994), embora o regime de remuneração seja parte importante de um contrato de serviços, este documento possui diversas funções, como: especificar as necessidades do contratante; detalhar níveis de responsabilidade e autoridade; especificar acordos para variações das necessidades do contratante; definir regime de transferência de informações; expor e criar regra de alocação dos riscos do projeto; definir incentivos e recompensas à parte contratada; definir sanções à parte contratada em função do não atendimento de expectativas; e criar mecanismos de resolução de divergências.

O longo prazo dos contratos de terceirização logística dificulta a antecipação dos custos envolvidos na operação das atividades terceirizadas, surgindo assim custos não previstos no decorrer do processo. Diferenças entre os custos previstos e reais também podem ocorrer devido à superestimação do desempenho do prestador de serviço e a falhas na determinação das especificações, objetivos e definição das cláusulas contratuais por parte da contratante. Para Allen e Chandrashekar (2000), é impossível prever as eventuais mudanças à qual a cadeia de suprimentos está susceptível em longo prazo, reforçando que os contratos tradicionais não atendem às necessidades da terceirização logística.

Handley e Benton (2009) consideram que um contrato logístico tem duas funções fundamentais: coordenação e controle. As disposições de coordenação esclarecem as expectativas mútuas, delineando papéis, regras e procedimentos relacionados ao esforço conjunto para atingir metas coletivas (MELLEWIGT; MADHOK; WEIBEL, 2007; REUER; ARIÑO, 2007). Por outro lado, as disposições de controle determinam e influenciam o que as partes vão fazer (DAS; TENG, 1998). Finalmente, Argyres e Mayer (2007) salientam a necessidade do envolvimento de uma equipe multifuncional no desenho do contrato, pois vários grupos dentro da empresa têm capacidade singularmente qualificada para desenvolver determinadas disposições contratuais. Enfim, o maior desafio no desenho de um contrato logístico consiste em elaborar regras específicas o suficiente para proteger ambas as partes da negociação e, ao mesmo tempo, ser flexível para acomodar eventos inesperados. A próxima seção trata da questão da flexibilidade nos contratos de terceirização logística.

\section{A flexibilidade nos contratos de terceirização logística}

A decisão de terceirização logística é influenciada por variáveis externas (elementos econômicos, competição, viabilidade de operadores logísticos) sobre as quais a empresa possui pouco controle. Porém, essas variáveis têm consequência direta na empresa, ocasionando necessidades de mudanças. Para Cánez, Platts e Probert (2000), essas mudanças motivam o processo de terceirização. Como a terceirização logística é uma decisão eminentemente de longo prazo, as relações entre o cliente e os operadores logísticos também estão suscetíveis a tais mudanças.

As incertezas de mercado referentes à introdução de novas tecnologias, exigência de novos serviços, volatilidade dos preços, gastos com pessoal, impostos, taxas de câmbio e custo de capital dificultam o planejamento, ampliando a exposição ao risco de empresas contratantes e operadores logísticos (BREALEY; MAYERS, 2003). Assim, os contratos de terceirização logística devem ser flexíveis para permitir que a relação se adapte às possíveis mudanças (HONESS; CHANCE, 1996). Como a adaptabilidade nesse tipo de relacionamento não pode ser unilateral, mudanças na relação entre o contratante e a contratada requerem consentimento mútuo (BARTHÉLEMY; QUÉLIN, 2006). Por isto, os contratos de terceirização 
devem ser flexíveis, permitindo ajustes. A utilização de contratos de curto prazo seria mais simples do que a elaboração de contratos flexíveis de longo prazo. Entretanto, a tendência é que os contratos logísticos sejam de longo prazo devido às necessidades de investimentos e de estudos para a melhoria de processos que esse tipo de relação requer (SOLS; NOWICK; VERMA, 2007).

Um contrato de terceirização ideal especificaria todos os quesitos relativos a preço, quantidade, prazo e investimentos (KULATILAKA; MARKS, 1988). Entretanto, é impossível a previsão de todos os cenários em contratos de longo prazo, além dos altos custos de negociação e de informação (FOSTER, 1997). Assim, Kulatilaka e Marks (1988) reforçam a necessidade de um contrato flexível, que estabeleça opções para variação dos volumes de acordo com as condições de demanda, custos e a tecnologia vigente. A flexibilidade gera valor estratégico para o contrato, além de reduzir o risco da negociação.

Sols, Nowick e Verma (2007) consideram que os contratos logísticos devem especificar os resultados e metas esperadas pela contratante para os serviços terceirizados. 0 contrato de terceirização logística costuma ser detalhado em termos de preços e níveis de serviço, uma vez que fornece instrumentos para que as atividades terceirizadas sejam acompanhadas e monitoradas permanentemente (NOVAES, 2004).

Harris, Giunipero e Hult (1998) apontam para a criação de mecanismos de arbitragem como um dos desafios do desenho de um contrato de terceirização logística. 0 contrato deve ser flexível para se adaptar às mudanças, mantendo a competitividade organizacional e, ao mesmo tempo, detalhado para definir critérios de desempenho e permitir a gestão de custos (HANDLEY; BENTON, 2009). Os envolvidos no desenho do contrato devem compreender e especificar as principais cláusulas para evitar conflitos, minimizar custos e obter flexibilidade, tendo em consideração a legislação em todos seus níveis e o interesse de cada parte.

Os contratos de terceirização logística devem ser elaborados especificamente para cada caso, respeitando as particularidades de cada relação (JANÉ; OCHOA, 2006). Entretanto, Borison e Hamm (2005) afirmam que os envolvidos no desenho do contrato, geralmente, optam por modelos de contrato padrões para a terceirização. De acordo com os autores, a flexibilidade do contrato não costuma ser examinada, ou é examinada de forma incompleta. Em geral, uma das partes recusa a opção, requisitada pela outra parte, por considerar que a cláusula implicaria em maiores custos.
Foster (1998) sugere que, antes do desenho do contrato, seja estabelecida uma carta de intenções onde são firmadas as condições e procedimentos a serem adotados pelas partes na fase de implementação das operações terceirizadas. 0 autor propõe que a preparação do contrato se inicie após seis meses de operação. Um dos principais problemas da implementação é a falta de critérios de desempenho claros. Dessa forma, esta proposta permite que, antes da elaboração do contrato, as partes se conheçam e compreendam como será a operação logística terceirizada. De tal modo, os envolvidos no desenho do contrato podem identificar melhor as particularidades da relação e elaborar um contrato específico para o caso, com mecanismos de arbitragem que atendam às necessidades do cliente e sejam vantajosos para o operador logístico. Portanto, o estabelecimento da carta de intenções é uma flexibilidade que aumenta a probabilidade de sucesso da terceirização.

Segundo Borison e Hamm (2005), um contrato flexível oferece opções para que as partes envolvidas possam responder de forma apropriada às mudanças. Para os autores, o contrato de terceirização pode ser dividido em cinco áreas principais: i) mecanismo de remuneração; ii) prazo; iii) especificação de volumes; iv) especificação de cronogramas e lead-times; e v) confiabilidade. Apesar de a flexibilidade ser relevante em todas as áreas, os autores consideram que sua importância é maior para os critérios de prazo e especificação de volumes. 0 contrato deve conter cláusulas que possibilitem a rescisão do contrato ou sua prorrogação, bem como opções para o ajuste dos volumes devido a variações das demandas.

Barhélemy e Quélin (2006) consideram que um contrato de terceirização logística deve ter cinco tipos diferentes de cláusulas legais: i) cláusulas sobre o modelo de remuneração; ii) cláusulas para término de contrato; iii) cláusulas de incentivos; iv) cláusulas de flexibilidade; e v) cláusulas de controle. Harris, Giunipero e Hult (1998) afirmam que a flexibilidade de um contrato pode ser obtida a partir de quatro aspectos principais: i) flexibilidade de preços; ii) flexibilidade de renegociação; iii) cláusulas para rompimento de contrato; e iv) incentivos, recompensas e penalidades. A seguir, estes aspectos são analisados.

\subsection{Cláusulas de rompimento de contrato}

Monczka, Trent e Handfield (2002) destacam a importância de cláusulas de rescisão contratual, bem como de sanções ou medidas a serem adotadas no caso do não cumprimento de cláusulas contratuais. Um contrato de terceirização logística deve possuir cláusulas que determinem as condições para a sua rescisão, sendo que tais condições podem ser 
relacionadas à qualidade e ao desempenho do serviço prestado. Harris, Giunipero e Hult (1998) salientam que, sem o estabelecimento desse tipo de cláusula, a empresa contratante pode sofrer penalizações pela quebra de contrato, mesmo em casos de mau desempenho do operador logístico. Os contratos de terceirização não devem se restringir apenas a cláusulas relativas ao rompimento de contrato, mas também cláusulas que possibilitem sua prorrogação (BORISON; HAMM, 2005). Assim, o contrato se torna flexível com relação ao prazo.

\subsection{Flexibilidade de preços}

Em 1989, Beier (1989) já identificava a necessidade de incorporar, aos contratos logísticos, cláusulas de ajuste de preços (remuneração) de acordo com o desempenho das partes envolvidas. 0 autor ressaltava a incerteza do futuro da logística e indicava a incorporação de cláusulas que contribuíssem para a flexibilidade do contrato como uma fonte de vantagem competitiva. Esta conclusão, ainda, permanece atual.

Existem duas classes de contrato de terceirização logística, segundo os modelos de remuneração: i) contratos de remuneração fixa; e ii) contratos de remuneração variável (ABRAHÃO, 2005). Entre os contratos de remuneração fixa, destacam-se: 0 contrato por preço fixo e o contrato a custo mais remuneração fixa. No contrato por preço fixo, o risco é absorvido pelo operador logístico. Entretanto, no contrato a custo mais remuneração fixa, o risco é maior para a contratante e não há um mecanismo de estímulo à redução de custos por parte do operador.

Os contratos de remuneração variável dividem os riscos e lucros entre o contratante e o operador logístico. Em geral, é especificado um nível de atendimento a ser atingido, além de incentivos e penalidades. Os modelos de remuneração baseados no desempenho contemplam acordos contratuais onde aspectos quantificáveis do nível de serviço influenciam o montante a ser pago (PARISH, 1997). Tal mecanismo se operacionaliza por meio da aplicação de bônus ou penalizações ao operador logístico. 0 uso de indicadores de desempenho no modelo de remuneração é indicado como recurso para garantir o atendimento do nível de serviço acordado entre as partes. Outro desafio consiste em alocar os riscos da operação de forma a garantir retornos justos e incentivos à redução de custos.

Sistemas de pagamento que sigam a lógica dos modelos de remuneração por incentivo são aplicáveis desde que os índices de desempenho sejam passíveis de mensuração e conferência (ABRAHÃO, 2005). Dessa forma, abordagens que agregam incentivos e penalidades referentes ao atendimento dos índices de desempenho, bem como às metas de custos, geralmente apresentam bons resultados, além de trazer flexibilidade ao contrato.

0 modelo de remuneração adotado em um processo de terceirização logística influencia diretamente a flexibilidade de preços do contrato. A inclusão de mecanismos de ajustes de preços reduz os custos para a elaboração do contrato, uma vez que deixa de ser necessária a realização de estudos de cenários na tentativa de prever as possíveis mudanças para a estimação de um preço fixo (HARRIS; GIUNIPERO; HULT, 1998). A possibilidade de mudanças no valor a ser remunerado permite a flexibilidade de preço, que poderá ser ajustado de acordo com as circunstâncias. Com isto, reduz-se a possibilidade de oportunismo por parte da contratada (beneficiar-se de preço inferior ao de mercado) ou do operador logístico (beneficiar-se de preço superior ao de mercado).

\subsection{Flexibilidade de renegociação}

Uma das questões presentes na gestão de relacionamentos entre empresas é a renegociação das bases contratuais (ABRAHÃO, 2005). A renegociação pode ocorrer devido à existência de conflitos baseados em desalinhamentos de políticas de governança, para a renovação de um contrato ou para o ajuste de uma cláusula devido a mudanças das variáveis que influenciam as condições da relação (REUER; ARIÑO, 2002).

Cláusulas que especificam as condições de renegociação contribuem para a adaptabilidade do contrato às mudanças da relação entre o contratante e o operador logístico (HARRIS; GIUNIPERO; HULT, 1998). Os procedimentos de renegociação permitem que as partes levem em consideração informações atualizadas, especialmente, em um ambiente de rápidas transformações, como o da cadeia de suprimentos.

Alguns contratos determinam as condições nas quais as renegociações devem ocorrer, além de especificar como estas devem proceder. Uma cláusula relativa à renegociação pode especificar, por exemplo, a data em que a renegociação deve ocorrer. Richardson (1993) sugere que sejam marcados de dois a três encontros anuais entre as partes, de modo a verificar se estas estão satisfeitas com as condições do contrato ou se há necessidade de renegociações.

Harris, Giunipero e Hult (1998) salientam a importância das cláusulas de renegociação para a flexibilidade do contrato. Os autores reforçam que, mesmo que estas cláusulas não sejam especificadas, em caso de contratos de longo prazo (como os de terceirização logística), haverá a necessidade de renegociação. 


\subsection{Incentivos e penalidades}

Devido a sua complexidade, o processo de terceirização requer contratos detalhados e flexíveis com cláusulas que tratem de condições futuras, mesmo que estas não sejam previsíveis. Os mecanismos de incentivos e penalidade são boas ferramentas para garantir o desenvolvimento do relacionamento e a melhoria do desempenho, mesmo em condições sujeitas à mudança (ANDERSSON; NORRMAN, 2002). À medida que a responsabilidade dos operadores sobre o sistema logístico aumenta, as cláusulas de incentivos e penalidades tornam-se mais importantes para os contratos de terceirização logística (NOVAES, 2004). Tais cláusulas devem estimular o operador logístico, ao longo de toda a duração do contrato (SOLS; NOWICK; VERMA, 2007).

As cláusulas de incentivo têm como objetivo estimular o contratado a atingir objetivos e metas referentes a questões técnicas, cronogramas, prazos, custos ou qualidade. Segundo Harris, Giunipero e Hult (1998), os incentivos costumam ser estabelecidos a partir da adoção de mecanismos de remunerações ou bônus com o intuito de atingir melhor desempenho. Os autores (HARRIS; GIUNIPERO; HULT; 1998) mencionam dois tipos de cláusulas de incentivos: i) as cláusulas que definem o compartilhamento dos benefícios, obtidos a partir da melhoria do desempenho, entre o contratante e a contratada; e ii) a remuneração baseada em indicadores de desempenho.

Há também as cláusulas de penalidades para o caso de que as metas esperadas não sejam atingidas. Além de penalidades, os contratos estabelecem que, no caso do não atendimento das metas especificadas, o operador deve analisar a atividade e apresentar uma solução para o problema (ANDERSSON; NORRMAN, 2002). Este tipo de cláusula não tem uma postura punitiva, mas sim de estimular o operador a adotar uma postura proativa.

0 estabelecimento de cláusulas de penalidades e incentivos contribui para a adaptabilidade do contrato a diferentes situações, aumentando, assim, sua flexibilidade. Além disso, a definição de regras claras (de penalidades ou de incentivos) para o funcionamento contratual age como garantia de estabilidade do contrato.

\subsection{Sintese das especificidades do contrato de terceirização logística}

Esta seção traz a síntese de elementos que permitem a diferenciação dos contratos de terceirização logística dos contratos tradicionais adotados pelos setores de Compras, enfatizando os aspectos que garantem a flexibilidade contratual. 0 Quadro 1 apresenta os elementos de flexibilidade no desenvolvimento de contratos logísticos identificados na literatura, sua definição e os autores que as trabalharam.

\section{Metodologia}

Esta pesquisa tem cunho qualitativo, sendo adotado o estudo de caso como estratégia de investigação. Seu escopo consiste em identificar como se estruturou o processo de contratação de um operador logístico em uma empresa de telecomunicações de capital nacional. Assim, o trabalho busca responder à seguinte questão: que elementos permitem a flexibilidade no

Quadro 1. Elementos de flexibilidade no desenvolvimento do contrato logístico.

\begin{tabular}{|c|c|c|}
\hline Elemento & Descrição & Autor \\
\hline $\begin{array}{l}\text { Prazo de } \\
\text { contrato }\end{array}$ & Prazos extensos para amortização de investimentos longos. & $\begin{array}{l}\text { Abrahão (2005), Borison e Hamm (2005), } \\
\text { Lieb e Bentz (2005) }\end{array}$ \\
\hline $\begin{array}{l}\text { Flexibilidade no } \\
\text { prazo do contrato }\end{array}$ & Cláusulas que permitem prorrogação do prazo do contrato. & Borison e Hamm (2005) \\
\hline $\begin{array}{l}\text { Especificações } \\
\text { técnicas }\end{array}$ & $\begin{array}{l}\text { Definição de metas, padrões de qualidade, quantidade (volumes), } \\
\text { opções para ajuste dos volumes devido a variações na demanda, } \\
\text { prazos, cronogramas, investimentos e preços. }\end{array}$ & $\begin{array}{l}\text { Kulatilaka e Marks (1998), } \\
\text { Borison e Hamm (2005) }\end{array}$ \\
\hline $\begin{array}{l}\text { Cláusula de } \\
\text { rompimento } \\
\text { do contrato }\end{array}$ & $\begin{array}{l}\text { Determina as condições para a rescisão do contrato no caso de } \\
\text { não cumprimento de cláusulas contratuais ou de acordo com a } \\
\text { qualidade da prestação de serviços. }\end{array}$ & $\begin{array}{c}\text { Harris, Giunipero e Hult (1998), Boyson (1999), } \\
\text { Monczka, Trent e Handfield (2002), } \\
\text { Borison e Hamm (2005) }\end{array}$ \\
\hline $\begin{array}{l}\text { Mecanismos de } \\
\text { remuneração }\end{array}$ & $\begin{array}{l}\text { É indicada a remuneração variável que divide riscos e lucros entre } \\
\text { contratante e operador, permitindo ainda a flexibilidade de preço. }\end{array}$ & $\begin{array}{l}\text { Beier (1989), Ward e Chapman (1994), } \\
\text { Parish (1997), Abrahão (2005) }\end{array}$ \\
\hline $\begin{array}{l}\text { Cláusulas de } \\
\text { renegociação }\end{array}$ & $\begin{array}{l}\text { Condições para renegociação da base contratual, especificando } \\
\text { os procedimentos quanto a reuniões e negociações. }\end{array}$ & $\begin{array}{c}\text { Richardson (1993), Harris, Giunipero e Hult (1998), } \\
\text { Reuer e Ariño (2002), Brealey e Mayers (2003), } \\
\text { Abrahão (2005), Wang e Tsao (2005) }\end{array}$ \\
\hline $\begin{array}{l}\text { Incentivos e } \\
\text { penalidades }\end{array}$ & $\begin{array}{l}\text { Garantem o desenvolvimento do relacionamento e melhoria do } \\
\text { desempenho, visando estimular o contratado a atingir objetivos } \\
\text { e metas. }\end{array}$ & $\begin{array}{l}\text { Andersson e Norman (2002), Novaes (2004), } \\
\text { Sols, Nowick e Verma (2007) }\end{array}$ \\
\hline $\begin{array}{l}\text { Indicadores de } \\
\text { desempenho }\end{array}$ & $\begin{array}{l}\text { Permitem o acompanhamento e monitoramento dos serviços } \\
\text { terceirizados. }\end{array}$ & $\begin{array}{l}\text { Novaes (2004), Abrahão (2005), } \\
\text { Sols, Nowick e Verma (2007) }\end{array}$ \\
\hline
\end{tabular}


desenvolvimento de contrato de terceirização logística? Ainda são poucas as pesquisas sobre contratos de terceirização logística (FOSTER, 1997; JANÉ; OCHOA, 2006), de modo que o trabalho proporciona uma visão geral sobre o tema em estudo, levantando questões e hipóteses para futuras pesquisas.

Foram realizadas dez entrevistas com cinco executivos envolvidos no processo. 0 protocolo do estudo de caso foi desenvolvido com base em entrevistas não estruturadas realizadas com o pessoal envolvido (da empresa e do operador selecionado), estudo dos documentos utilizados e análise do processo. As questões foram elaboradas de acordo com as categorias apresentadas no Quadro 1. A validade de face e de conteúdo foi assegurada por dois consultores e um acadêmico. Em seguida, foram agendadas entrevistas com os líderes dos processos terceirizados e seus pares do operador logístico. Foram entrevistados, na empresa contratante, o gerente responsável pela condução do processo de seleção e dois analistas que auxiliaram nos trâmites burocráticos. No operador logístico, foram realizadas entrevistas com o gerente responsável pela gestão do contrato e um analista, alocado na contratante, que é responsável pela supervisão das operações diárias.

A principal fonte de dados foram entrevistas gravadas e transcritas pelos pesquisadores. Dado o caráter descritivo e explicativo do estudo de caso proposto, a técnica de análise foi emparelhamento de padrões (do inglês, pattern-matching) entre os resultados obtidos e as teorias que estruturam o referencial desta pesquisa, o que direcionou a escolha da análise de conteúdo como ferramental analítico básico. Além das entrevistas, também foram adotadas fontes de evidências documentais, como os sites das empresas, reportagens e artigos sobre o setor. A partir das análises, foi gerada uma lista de cláusulas do contrato a serem aperfeiçoadas. Esses itens foram estudados pelos autores deste artigo e consolidados. Após essa consolidação, os autores voltaram a se reunir com os grupos anteriores nas duas empresas para avaliar de que maneira as cláusulas atuais influenciavam a implementação e quais as possiveis soluções. 0 estudo foi desenvolvido no período de junho/setembro 2009.

\section{Estudo de caso}

Nesta seção, é feita uma contextualização da empresa estudada e, em seguida, é apresentada a análise dos resultados do estudo de caso.

\subsection{Descrição da unidade de análise}

A empresa referenciada neste estudo de caso oferece ao mercado soluções integradas em serviços de telecomunicação, atendendo demandas das mais diversas, tais como: ligações locais, ligações de longa distância (nacional e internacional), comunicação de dados para grandes empresas, serviços de call center e de telefonia móvel. A organização possui uma grande base de clientes distribuídos pelo território nacional e utiliza como estratégia de marketing fornecer todos os serviços de telecomunicação (fixa, móvel e banda larga) simultaneamente e a um custo mais baixo. A organização é considerada líder em seu mercado de atuação.

A empresa surgiu do Programa Nacional de Desestatização, que tinha como objetivo privatizar empresas públicas. Em 1998, o Ministério das Comunicações decidiu dividir a empresa federal de telefonia em doze companhias e, desta divisão, surgiu a organização em estudo. Por se tratar de uma empresa de grande porte com modelos de operação logística diferenciados, foi analisada, apenas, a contratação do operador logístico responsável pela armazenagem e distribuição de materiais de manutenção para rede de uma das áreas fim da empresa. 0 operador logístico é responsável pelas estruturas de centros de distribuição, centros de armazenagem e operações de transportes.

\subsection{Processo de seleção do operador logístico}

0 processo de seleção do operador logístico pela empresa cumpriu os passos estabelecidos por seus executivos. Inicialmente, foi elaborada uma lista com 135 empresas prestadoras de serviços logísticos $3 \mathrm{PL}$, uma vez que este foi o perfil de relacionamento definido pela contratante. A partir desta lista, foram pré-selecionados 35 potenciais candidatos a operadores logísticos aos quais foram enviados requerimentos de informação (request for information - RFI). É importante salientar que o número de operadores a receber o RFl é superior ao recomendado por Jharkharia e Shankar (2007), os quais sugerem o envio do requerimento de informação a um grupo de aproximadamente 10 operadores logísticos. 0 processo de aplicação do RFl durou três semanas, estando assim em concordância com as recomendações de Bentz (2006). Com base nas respostas aos RFl, procedeu-se a avaliação inicial dos operadores segundo os requisitos e padrões mínimos de atendimento, sendo eliminados os candidatos que não atendiam a tais condições. Cinco operadores logísticos foram selecionados dentro de critérios preestabelecidos após recebimento das informações advindas do RFI. 
Foram enviados requerimentos de proposta (request for proposal - RFP) para os cinco operadores candidatos. As respostas a esses questionários fornecem as informações qualitativas e quantitativas sobre os operadores logísticos, que são utilizadas para a comparação entre os candidatos. A partir do processo de elaboração do RFP e das respostas obtidas pelos operadores, a empresa contratante passou a ter acesso a informações relativas à estrutura de custos sobre a qual funcionaria a operação, à estrutura de remuneração e às tabelas de preços para o nível de atendimento padronizado. Desta forma, foram obtidos os preços unitários a serem pagos ao operador logístico. Com esses dados, foi realizada a análise de viabilidade econômica da terceirização da operação de transportes, dos centros de distribuição e de armazenagem. Nesta etapa, foram selecionados três operadores logísticos para a fase de visitas técnicas. Foram agendadas visitas técnicas e inspeções locais a esses três operadores candidatos e a alguns de seus clientes. Além da inspeção das instalações e operações, verificou-se a consistência das informações recebidas pelo RFP. Enfim, realizou-se a seleção final do operador logístico de acordo com os critérios estabelecidos pela empresa contratante.

\subsection{Resultados da análise do estudo de caso}

Em vista da introdução teórica discutida, das entrevistas com executivos da empresa e do operador selecionado e do estudo dos documentos utilizados no processo, foi possível elaborar a análise de conteúdo e o desenvolvimento do caso.

0 período de negociação do contrato com o operador logístico selecionado durou aproximadamente três meses. 0 processo de desenho do contrato foi desempenhado por uma equipe composta por integrantes dos departamentos de Engenharia, Logística, Materiais e Compras, cabendo ao setor de Compras a liderança do processo. Observou-se que, durante a elaboração do contrato de serviços logísticos, foram desenvolvidas várias versões a partir de constante negociação entre as partes. A contratação adotou preliminarmente o tradicional modelo de contrato de compras, que posteriormente foi adaptado para a contratação logística.

A versão final do contrato entre a empresa de telecomunicações e o operador logístico foi composta por cláusulas que definem e estabelecem os seguintes elementos: prazo de validade, disponibilidade de atendimento (24 horas por dia, 7 dias por semana), recursos humanos dedicados, cronogramas para implantação dos serviços, níveis de controle gerencial, custos, especificações técnicas de equipamentos, descrição das atividades previstas, prazos de entrega, prazos de pagamento, níveis de segurança, local de faturamento e fórmulas de reajuste de preços.

Identificou-se que a empresa contratante não trata o operador logístico como uma extensão do seu próprio negócio. Mesmo que o processo terceirizado seja responsável por grande parte dos seus gastos com logística, a contratante não desenvolveu uma parceria estratégica com o operador. Porém, tiveram o cuidado de elaborar um contrato que servisse para regular as relações entre as partes. Dessa forma, as orientações de Van Hoeck (2000) e Jané e Ochoa (2006), que enfatizam a necessidade de pautar a relação entre o operador e a contratante por meio de um contrato de terceirização, foram devidamente seguidas. Entretanto, foram incluídos neste contrato apenas dois dos elementos de flexibilidade propostos no Quadro 1: i) estabelecimento do prazo do contrato; e ii) adoção de mecanismo de remuneração variável.

0 prazo de contratação foi negociado e definido em um ano. No entanto, o contratado alega que esse prazo não é suficiente para a amortização dos investimentos exigidos para atender o processo terceirizado. Segundo o gerente do operador logístico, seria necessário um prazo de contrato mais longo para permitir a amortização dos investimentos. Assim, configura-se a situação prescrita por Lieb e Bentz (2005) quanto à necessidade de flexibilização do prazo de contratação, especialmente em casos com alta especificidade e que exigem maiores investimentos por parte da contratada.

Não foram estabelecidos, no contrato, indicadores de desempenho para verificar a atuação do operador logístico contratado. Sem indicadores para mensurar o desempenho da operação logística, os contratantes abriram mão de definir metas e critérios de controle que permitiriam o melhor acompanhamento e monitoramento das atividades terceirizadas. Ainda, não foram observadas cláusulas bem definidas em relação a incentivos e penalidades. A adoção de mecanismos de incentivos e penalidades estimula a melhoria do desempenho e a motivação do operador logístico, reduzindo o risco de um comportamento irregular por sua parte.

0 aspecto de flexibilidade de preços foi coberto no contrato por meio da adoção de cláusulas com fórmulas de reajuste de preços. Porém, o sistema de remuneração se dá a partir de um mecanismo de remuneração fixa: o preço unitário foi negociado e fixado em contrato, sendo o pagamento proporcional ao volume de serviço executado pela contratada. Como não foram estabelecidos indicadores de desempenho e metas a serem atingidas, não é possível adotar o sistema de remuneração variável, em que o nível de 
serviço influencia o montante a ser pago. Nesse caso, seria necessário o estabelecimento de indicadores quantificáveis para a mensuração do nível de serviço. Destaca-se, entretanto, que foram definidas, em contrato, fórmulas para o reajuste dos preços unitários, o que permite certa flexibilidade. Contudo, os executivos entrevistados relataram a pretensão de introduzir, a partir de futuras renegociações, indicadores de desempenho no modelo de remuneração do operador logístico. Assim, será possível garantir atendimento no nível de serviço.

Foi verificado que as cláusulas de rompimento do contrato não são claras e que as condições que permitem a rescisão estão mal esclarecidas, infringindo uma das principais recomendações de Monczka, Trent e Handfield (2002). Também foi constatada a necessidade de aprimoramento das cláusulas do contrato que definem as condições de renegociação, de modo a permitir que as partes considerem informações atualizadas.

0 Quadro 2 sintetiza os resultados obtidos da análise do contrato que rege o serviço do operador logístico selecionado face ao instrumento metodológico utilizado pelos autores deste trabalho, seguindo os elementos de flexibilidade apresentados previamente no Quadro 1.

Da análise do contrato referente ao presente estudo de caso, verifica-se que foram adotados poucos dos elementos de flexibilidade propostos nesta pesquisa. A seguir são sugeridas recomendações para melhoria da gestão do contrato da unidade de análise de acordo com os elementos de flexibilidade que não foram considerados no contrato logístico analisado (Quadro 2). Deve ser ressaltado que houve o cuidado de apresentar sugestões para todos os elementos não contemplados e suportá-los com o devido apoio teórico.
Em relação à flexibilidade no prazo do contrato, evidencia-se a necessidade de uma mudança de mentalidade dos contratantes quando à elaboração de um novo contrato em uma futura renovação. É importante que a empresa contratante tenha a preocupação de considerar o operador logístico como um parceiro estratégico, tal como sugerido por Coughlan et al. (2002). Também deve ser redigido um contrato específico para contratação do parceiro logístico, uma vez que não deve ser utilizado um modelo padrão de contratação de compras, como foi feito pela organização. A prática adotada contraria autores como Beier (1989) e Craig e Wilmott (2005), que são enfáticos ao afirmar a necessidade da utilização de contratos específicos.

A falta da utilização de indicadores de desempenho pela organização para a medição do desempenho contratado despreza práticas recomendadas por autores como Parish (1997) e Harris, Giunipero e Hult (1998). A implantação de um sistema de indicadores que meça a operação é de fundamental importância. Com a adoção desse sistema, devem ser estabelecidas metas que sirvam de critério para remuneração ao operador logístico e atendam, também, ao elemento de incentivos e penalidades. Tais bonificações devem ser contidas em uma tabela a ser criada e negociada entre as partes. A medição da operação do processo logístico terceirizado permitirá o estabelecimento de correções e aprimoramento dos desvios encontrados no processo. Após a introdução da medição, outras ferramentas gerenciais, tais como seis sigma, poderão ser utilizadas para estabelecer projetos que visem resolver os hiatos entre os resultados obtidos e as metas para os diferentes indicadores selecionados (MELLO, 2003).

0 contrato analisado não tem cláusulas de rompimento ou rescisão. Assim sendo, aconselha-se

Quadro 2. Elementos de flexibilidade considerados no contrato logístico analisado.

\begin{tabular}{|c|c|}
\hline Elemento & Considerado no contrato da unidade de análise \\
\hline $\begin{array}{l}\text { Prazo de } \\
\text { contrato }\end{array}$ & $\begin{array}{l}\text { Sim. } 0 \text { prazo de contratação foi negociado em um ano mas seria necessário um prazo mais longo para permitir a } \\
\text { amortização dos investimentos. }\end{array}$ \\
\hline $\begin{array}{l}\text { Flexibilidade no } \\
\text { prazo do contrato }\end{array}$ & $\begin{array}{l}\text { Não há cláusulas que facilitem a renegociação do prazo do contrato, de modo que traga a flexibilidade para esta } \\
\text { questão. }\end{array}$ \\
\hline $\begin{array}{l}\text { Especificações } \\
\text { técnicas }\end{array}$ & $\begin{array}{l}\text { Sim. A versão final do contrato foi composta por cláusulas que definem: disponibilidade de atendimetno, recursos } \\
\text { humanos dedicados, especificações técnicas de equipamentos, descrição das atividades previstas e prazos de entrega. }\end{array}$ \\
\hline $\begin{array}{l}\text { Cláusula de } \\
\text { rompimento } \\
\text { do contrato }\end{array}$ & $\begin{array}{l}\text { Não. As cláusulas de rompimento do contrato não são claras e as condições que permitem a rescisão estão mal } \\
\text { esclarecidas. }\end{array}$ \\
\hline $\begin{array}{l}\text { Mecanismos de } \\
\text { remuneração }\end{array}$ & $\begin{array}{l}\text { Sim. } 0 \text { contrato estabelece um mecanismo para remuneração fixa, porém a flexibilidade de preços foi coberta por meio } \\
\text { da adoção de cláusulas com fórmulas de reajuste de preços. }\end{array}$ \\
\hline $\begin{array}{l}\text { Cláusulas de } \\
\text { renegociação }\end{array}$ & Não. Há a necessidade de aprimoramento das cláusulas que definem as condições de renegociação do contrato. \\
\hline $\begin{array}{l}\text { Incentivos e } \\
\text { penalidades }\end{array}$ & Não foram definidas cláusulas relacionadas a sistemas de incentivos e penalidades. \\
\hline $\begin{array}{l}\text { Indicadores de } \\
\text { desempenho }\end{array}$ & $\begin{array}{l}\text { Não foram estabelecidos indicadores para verificar o desempenho do operador logístico, dificultando o acompanhamento } \\
\text { e monitoramento das atividades terceirizadas. Há planos para introduzir indicadores de desempenho. }\end{array}$ \\
\hline
\end{tabular}


a criação de cláusulas de rompimento de contrato que sejam claras e bem definidas, criando "portas de escape" que permitam possibilidades de adaptação para problemas futuros ou mudanças de cenário. Outra recomendação é de que se definam cláusulas de incentivo e penalidades, pois o contrato não dispõe de tais elementos que são recomendados por autores como Harris, Giunipero e Hult (1998) e Monczka, Trent e Handfield (2002).

A empresa deve re-estudar esse processo de terceirização logística, aproveitando essa experiência para identificar erros e acertos. Assim, depois de implantadas as sugestões de melhoria, devem ser transferidas as melhores práticas para outros setores da organização que também contratem prestadores de serviços logísticos.

Uma última recomendação diz respeito à análise dos prazos do contrato. A empresa deve se antecipar a uma provável solicitação de alongamento de prazos por parte do contratante, preparando-se para uma decisão madura e consciente sobre a validade ou não de atender tal pedido. Portanto, devem ser seguidas as propostas de Lieb e Bentz (2005) referentes à flexibilização do prazo de contratação, considerando a especificidade e a necessidade de investimentos do contrato. Logo, a decisão de flexibilizar os prazos de contratação exigirá o redesenho no contrato. Tal alteração permitirá um possível ganho para as partes com impactos na melhoria do desempenho global do contrato em análise.

\section{Considerações finais}

A terceirização logística e, consequentemente, a contratação de operadores logísticos são processos complexos devido a seus impactos no desempenho organizacional e ao alto investimento de capital envolvido nessas operações. Um contrato mal redigido terá efeitos danosos na competitividade organizacional e uma ruptura no processo trará sequelas para o organismo produtivo da empresa. 0 presente estudo se insere nos esforços da academia em discutir o processo de terceirização e contratação de operadores logísticos, tendo adotado o estudo de caso como estratégia de investigação.

0 estudo de caso analisou o processo de contratação de um operador logístico por uma empresa líder de mercado no setor de telecomunicações. A unidade de análise oferece seus serviços para clientes em todo território nacional, e o desempenho de seu processo logístico influencia diretamente o desempenho organizacional. As operações logísticas da empresa são complexas, de modo que a organização adota modelos de operação logística diferenciados.
Por isso, foi analisada apenas a contratação do operador logístico responsável pela armazenagem e distribuição de materiais de manutenção para rede de uma das áreas fim da empresa. A importância da organização no mercado de telecomunicações e a relevância de seu processo logístico garantem a representatividade do caso.

No desenvolvimento do estudo de caso, foram identificadas as possíveis causas de falhas no processo de elaboração do contrato do prestador do serviço, sendo sugeridas providências para melhorar implantações semelhantes. A análise propiciou uma visão dos principais problemas e soluções em casos de contratação de operadores logísticos, discutindo aspectos relevantes que influenciam o êxito da contratação e o gerenciamento desse tipo de processo.

Uma falha primordial do caso em análise refere-se à falta da definição da estratégia a ser seguida pela organização em relação ao modelo de contratação. A definição da estratégia é fundamental, uma vez que a modelagem do contrato deve estar alinhada à estratégia organizacional. É fundamental o alinhamento entre o escopo da terceirização e a estratégia da cadeia de suprimentos e da organização.

Poucos elementos que promovem a flexibilidade do contrato de terceirização logística foram adotados pela organização analisada. Destaque para a ausência de um sistema de indicadores que permita a avaliação do processo e do grau de eficiência do prestador de serviços. Essa é uma definição importante que influencia a escolha do modelo de contratação a ser seguido.

Outro ponto essencial é o entendimento por parte da organização de que a contratação de um operador logístico é uma decisão que deve se coadunar com os objetivos estratégicos da empresa, não sendo mera compra de um serviço. Portanto, deve-se evitar que a contratação utilize o modelo padrão de compras. Acredita-se que no momento em que essas observações principais forem consideradas, as demais definições serão mais facilmente asseguradas. Na organização analisada, é importante que estes e os demais pontos considerados ao longo do artigo sejam analisados, repensados e, depois de implantadas as sugestões de melhoria, sejam transferidas as melhores práticas para outros setores da organização que também contratam operadores logísticos.

Em suma, a importância desta pesquisa devese, sobretudo, ao levantamento de elementos relevantes no processo de elaboração de contratos de operadores logísticos por parte das organizações e das recomendações realizadas, que podem auxiliar outras empresas a terem êxito em processos semelhantes. 


\section{Referências}

ABRAHÃO, F. O contrato de prestação de serviços logísticos como instrumento de alocação de riscos operacionais: um estudo de caso. 2005. 119 f. Dissertação (Mestrado em Administração de Empresas)-Universidade Federal do Rio de Janeiro, Rio de Janeiro, 2005.

ALLEN, S.; CHANDRASHEKAR, A. Outsourcing services: the contract is just the beginning. Business Horizons, p. 25-34, 2000. http://dx.doi.org/10.1016/S00076813(00)88558-4

ANDERSSON, D.; NORRMAN, A. Procurement of logistics services: a minute work or a multi-year project? European Journal of Purchasing \& Supply Chain Management, n. 8, p. 3-14, 2002.

ARGYRES, N.; MAYER, K. Contract design as a firm capability: an integration of learning and transaction cost perspectives. Academy of Management Review, v. 32, n. 4, p. 1060-1077, 2007. http://dx.doi.org/10.5465/ AMR.2007.26585739

BARNEY, J.; HERSTERLY, W. Economia das Organizações: entendendo a relação entre organizações e a análise econômica. In: Nota Técnica In: CLEGG, S.; HARDY, C; NORD, D. (Orgs.). Handbook de estudos organizacionais. São Paulo: Atlas, 2004. v. 3, p. 131-179.

BARROS, M. Terceirização Logística no Brasil. Instituto de Logística e Supply Chain, 2009. Working paper llos. Disponivel em: <http://www.ilos.com.br/site/index. php?option=com_content\&task=view\&tid=738\&ttem id=279>. Acesso em: mar. 2011.

BARTHÉLEMY, J. The seven deadly sins of outsourcing. Academy of Management Executive, v. 17, n. 2, p. 87-98, 2003. http://dx.doi.org/10.5465/AME.2003.10025203

BARTHÉlEMY, J.; QUÉLIN, B. Complexity of Outsourcing Contracts and Ex Post Transaction Costs: An Empirical Investigation. Journal of Management Studies, v. 43, n. 8, p. 1775-97, 2006. http://dx.doi.org/10.1111/j.14676486.2006.00658.x

BEIER, F. J. Transportation contracts and the experience effect: a framework for future research. Journal of Business Logistics, v. 10, n. 2, p. 73-89, 1989.

BERMAN, J. 3PL news: annual 3PL study indicates industry is showing post-recession growth signs. Logistics management, 2010. Disponível em: <http://www. logisticsmgmt.com/article/3pl_news_annual_3pl_study_ shows_industry_is_showing_post-recession_growth_s/>. Acesso em: mar. 2011.

BENTZ, B. So you think you want to outsource? Logistics Today, v. 47, n. 5, p. 24-32, 2006.

BORISON, A.; HAMM, G. Better power contracts: using flexibility to increase value. The Electricity Journal, v. 18, n. 10, 2005. http://dx.doi.org/10.1016/j.tej.2005.10.010

BOT, B.; NEUMANN, C. Growing pains for logistics outsourcers. The McKinsey Quarterly, v. 2, p. 24-32, 2007.

BOYSON, S. Managing effective third party logistics relationships: what does it take? Journal of Business Logistics, v. 20, n. 1, p. 73, 1999.

BREALEY, R.; MYERS, S. Principles of Corporate Finance. 7th ed. McGraw-Hill Irwin, 2003.

CÁNEZ, L; PLATTS, K; PROBERT, D. Developing a framework for make-or-buy decisions. International Journal of Operations \& Production Management, v. 30, n. 11, p. 1313-30, 2000.
CENTRO DE ESTUDOS EM LOGÍSTICA - CEL. Indicadores sobre Prestadores de Serviços Logísticos. llos, 2008. Disponivel em: <http://www.ilos.com.br/site/index. php?option=com_deeppockets $>$. Acesso em: 16 mar. 2009.

CHEN, F.; HUM, S.; SUN, J. Analysis of third-party warehousing contracts with commitments. European Journal of Operational Research, v. 131, p. 603-610, 2001. http:// dx.doi.org/10.1016/S0377-2217(00)00102-8

COUGHLAN, A. et al. Canais de marketing e distribuição. Porto Alegre: Bookman, 2002.

CRAIG, D.; WILLMOTT, P. Outsourcing grows up. The McKinsey Quarterly, n. 1, 2005.

DAS, T.; TENG, B. Between trust and control: developing confidence in partner cooperation alliances. Academy of Management Review, v. 23, p. 491-512, 1998.

DIBENEDETTO, B. Global 3PLs grew 6.5\%. The Journal of Commerce, v. 1, n. 3, 2009. Disponivel em: <www.joc. com>. Acesso em: 20 fev. 2009.

ELLRAM, L.; TATE, W.; BILLINGTON, C. Offshore outsourcing of professional services: a transaction cost economic perspective. Journal of Operations Management, v. 26 , n. 2, p. 148-163, 2008. http://dx.doi.org/10.1016/j. jom.2007.02.008

FOSTER, T. Contracts? We don't need no stinkin' contracts. Logistics Management and Distribution Report, v.37, n. 12, p. 24-38, 1998.

FOSTER, T. Make logistics contracts work for you. Distribution, v. 96, n. 7, p. 55, 1997.

HANDLEY, S.; Benton, W. Unlocking the business outsourcing process model. Journal of Operations Management, v. 27, p. 344-361, 2009. http://dx.doi.org/10.1016/j. jom.2008.11.002

HARRIS, A.; GIUNIPERO, L.; HULT, G. Impact of organizational and contract flexibility on outsourcing contracts. Industrial Marketing Management, v. 27, p. 373-384, 1998. http://dx.doi.org/10.1016/S00198501(97)00085-0

HINGLEY, M. Power to all our friends? Living the imbalance in supplier-retailer relationships. Industrial Marketing Management, v. 34, n. 2, p. 848-858, 2005. http:// dx.doi.org/10.1016/j.indmarman.2005.03.008

HONESS, S.; CHANCE, C. Outsourcing: a legal perspective on contract critical success factors. Information Security Technical Report, v. 1, n. 3, p. 57-58, 1996. http://dx.doi. org/10.1016/S1363-4127(96)90093-X

JANÉ, H.; OCHOA, A. The handbook of logistics contracts: a practical guide to a growing field. Hampshire: Macmillan Publishers, 2006.

JHARKHARIA, S.; SHANKAR, R. Selection of logistic service provider: an analytic network process (ANP) approach Omega: The international Journal of Management Science, v. 35, p. 274-289, 2007.

KULATILAKA, N.; MARKS, S. The strategic value of flexibility: reducing the ability to compromise. The American Economic Review, v. 78, n. 3, p. 574-80, 1988.

LIEB, R.; BENTZ, B. The Year 2004 Survey: CEO Perspectives on the Current Status and Future Prospects of the Third Party Logistics Industry in the Asia-Pacif Region. 2005. Disponivel em: <http://web.cba.neu.edu/ lieb>. Acesso em: 2007. 
MALONI, M. J.; CARTER, C. R. Opportunities for research in third-party logistics. Transportation Journal, v. 45, n. 2, p. 23-38, 2006.

MALTZ, A. B.; ELLRAM, L. M. Total cost of relationship: an analytical framework for the logistics outsourcing decision. Journal of Business Logistics, v. 18, n. 1, p. 45-66, 1997.

MELLEWIGT, T.; MADHOK, A.; WEIBEL, A. Trust and formal contracts in interorganizational relationships - substitutes and complements. Managerial \& Decision Economics, v. 28 , n. 8 , p. $833-847,2007$. http://dx.doi.org/10.1002/ mde. 1321

MELLO, L. C. B. B. Seis Sigma: Análise de Metodológica de Implantação em uma Empresa Industrial. 2003. Dissertação (Mestrado em Engenharia de Produção)-Universidade Federal Fluminense, Niterói, 2003.

MONCZKA, R.; TRENT, R.; HANDFIELD, R. Purchasing and Supply Chain Management. 2nd ed. South-Western Thomson Learning, 2002

Novaes, A. Logística e Gerenciamento da Cadeia de Distribuição. Rio de Janeiro: Campus, 2004.

PALANEESWARAN, E. et al. Curing congenital construction industry disorders through relationally integrated supply chains. Building and Environment, n. 38, p. 571-582, 2003. http://dx.doi.org/10.1016/S03601323(02)00188-9

PARISH, R. J. Service level agreements as a contributor to TQM goals. Logistics Information Management, vol. 10, n. 6, p. 284-288, 1997. http://dx.doi. org/10.1108/09576059710187410

PRAHINSKI, C.; BENTON, W. Supplier evaluations: communication strategies to improve supplier performance. Journal of Operations Management, v. 22, n. 1, p. 39-62, 2004. http://dx.doi.org/10.1016/j. jom.2003.12.005

REUER, J. J.; ARIÑO, A. Contractual renegotiations in strategic alliances. Journal of Management, v. $8, \quad$ n. 1, p. 47-68, 2002. http://dx.doi. org/10.1177/014920630202800104
RICHARDSON, H. Contracts build relationships. Transportation and Distribution, v. 34, n. 11, p. 53-56, 1993.

ROBLES, L.; FISCHMANN, A. Características do Relacionamento entre Montadoras e Operadores Logísticos e a Prestação de Serviços de Logística Integrada na Indústria Automobilística no Brasil. In: ENCONTRO ANUAL DA ASSOCIAÇÃO DOS PROGRAMAS DE PÓS GRADUAÇÃO EM ADMINISTRAÇÃO - ENANPAD, 25., 2001, Campinas. Anais... Campinas: ANPAD, 2001.

SCHOENHERR, T. Outsourcing decisions in global supply chains: an exploratory multi-country survey. International Journal of Production Research, v. 48, n. 2, 343-78, 2010. http://dx.doi.org/10.1080/00207540903174908

SOLS, A.; NOWICK, D.; VERMA, D. Defining the fundamental framework of an effective performance-based logistics (PBL) contract. Engineering Management Journal, v. 19, n. 2, p. 40-49, 2007.

VAN HOEK, R. I. The purchasing and control of supplementary third-party logistics services. The Journal of Supply Chain Management, v. 36, n. 4, p14-26, 2000. http:// dx.doi.org/10.1111/j.1745-493X.2000.tb00082.x

WANG, Q.; TSAO, D. Supply contract with bidirectional options: The buyer's perspective. International Journal of Production Economics, n. 101, p. 30-52, 2006.

WARD, S.; CHAPMAN, C. Choosing contractor payment terms. International Journal of Project Management, v. 12, n. 4, p. 216-221, 1994. http://dx.doi.org/10.1016/02637863(94)90045-0

WATER, H.; PEET, H. A decision support model based on the Analytic Hierarchy Process for the Make or Buy decision in manufacturing. Journal of Purchasing and Supply Chain Management, v. 12, p. 258-71, 2006.

WILLIAMSON, 0. Outsourcing: transaction cost economics and supply chain management. Journal of Supply Chain Management, v. 44, n. 2, p. 5-16, 2008. http://dx.doi. $\operatorname{org} / 10.1111 / j .1745-493 X .2008 .00051 . x$

\title{
Flexibility elements in contracts of logistic outsourcing: the case of a telecommunications company
}

\begin{abstract}
This article examines, through the technique of case study, the process of logistics outsourcing in a Brazilian telecommunications company. Initially, the importance of contracts for outsourcing is analyzed according to the perspective of the transaction costs economics theory. The possible causes of imperfections in the contracting process are analyzed, and the steps to avoid the repetition of these mistakes in similar implementations are suggested. According to the authors' point of view, the acquired experience indicates that a primary error in outsourcing contracts refers to the lack of a strategy to be followed by the organization in relation to a contracting model. This definition is a fundamental step, since the contract must be aligned to the strategy.
\end{abstract}

Keywords:

Logistics. Outsourcing. Contracting. Third-party logistics. 